\title{
Deadly falls: operative versus nonoperative management of Type II odontoid process fracture in octogenarians
}

\author{
Christopher S. Graffeo, MD, Avital Perry, MD, Ross C. Puffer, MD, Lucas P. Carlstrom, MD, PhD, \\ Wendy Chang, MD, PhD, Grant W. Mallory, MD, and Michelle J. Clarke, MD \\ Department of Neurologic Surgery, Mayo Clinic, Rochester, Minnesota
}

\begin{abstract}
OBJECTIVE Type II odontoid fracture is a common injury among elderly patients, particularly given their predisposition toward low-energy falls. Previous studies have demonstrated a survival advantage following early surgery among patients older than 65 years, yet octogenarians represent a medically distinct and rapidly growing population. The authors compared operative and nonoperative management in patients older than 79 years.
\end{abstract}

METHODS A single-center prospectively maintained trauma database was reviewed using ICD-9 codes to identify octogenarians with C-2 cervical fractures between 1998 and 2014. Cervical CT images were independently reviewed by blinded neurosurgeons to confirm a Type II fracture pattern. Prospectively recorded outcomes included Glasgow Coma Scale (GCS) score, Abbreviated Injury Scale (AIS) score, Injury Severity Score (ISS), additional cervical fracture, and cord injury. Primary end points were mortality at 30 days and at 1 year. Statistical tests included the Student t-test, chisquare test, Fisher's exact test, Kaplan-Meier test, and Cox proportional hazard.

RESULTS A total of 111 patients met inclusion criteria (94 nonoperative and 17 operative [15 posterior and 2 anterior]). Mortality data were available for $100 \%$ of patients. The mean age was 87 years (range 80-104 years). Additional cervical fracture, spinal cord injury, GCS score, AIS score, and ISS were not associated with either management strategy at the time of presentation. The mean time to death or last follow-up was 22 months (range 0-129 months) and was nonsignificant between operative and nonoperative groups $(p=0.3$ ). Overall mortality was $13 \%$ in-hospital, $26 \%$ at 30 days, and $41 \%$ at 1 year. Nonoperative and operative mortality rates were not significant at any time point $(12 \%$ vs $18 \%, p=0.5$ [inhospital]; $27 \%$ vs $24 \%, p=0.8$ [30-day]; and $41 \%$ vs $41 \%, p=1.0$ [1-year]). Kaplan-Meier analysis did not demonstrate a survival advantage for either management strategy. Spinal cord injury, GCS score, AIS score, and ISS were significantly associated with 30-day and 1-year mortality; however, Cox modeling was not significant for any variable. Additional cervical fracture was not associated with increased mortality. The rate of nonhome disposition was not significant between the groups.

CONCLUSIONS Type II odontoid fracture is associated with high morbidity among octogenarians, with $41 \% 1$-year mortality independent of intervention-a dramatic decrease from actuarial survival rates for all 80-, 90-, and 100-year-old Americans. Poor outcome is associated with spinal cord injury, GCS score, AIS score, and ISS.

http://thejns.org/doi/abs/10.3171/2016.3.SPINE151202

KEY WORDS Type II odontoid fracture; elderly populations; spine trauma; nonoperative management; cervical

$\mathrm{F}$ RACTURE of the C-2 odontoid process is a common injury, accounting for $11 \%$ of all traumatic cervical spine injuries and more than $60 \%$ of spinal cord injuries in the elderly population..$^{26-28}$ Odontoid fractures are typically classified using the schema described by Anderson and D'Alonzo, which categorizes Type I injury as an isolated avulsion of the odontoid peg, Type II injury as a fracture through the odontoid "neck," and Type III injury as a fracture extending through the $\mathrm{C}-2$ body or odontoid base. $^{2}$

Evidence broadly supports nonoperative immobilization in Type I and Type III injuries, yet the optimal management of Type II fractures remains divisive, due to low fusion rates and risk of delayed myelopathy following nonunion. $6,8,14,19,24$ This controversy is particularly pronounced in elderly patients, who are at higher risk for both Type II

ABBREVIATIONS AIS = Abbreviated Injury Scale; GCS = Glasgow Coma Scale; ISS = Injury Severity Score; SCI = spinal cord injury. ACCOMPANYING EDITORIAL See pp 1-3. DOI: 10.3171/2016.4.SPINE16333.

SUBMITTED October 8, 2015. ACCEPTED March 11, 2016.

INCLUDE WHEN CITING Published online August 19, 2016; DOI: 10.3171/2016.3.SPINE151202. 
injury and poor postoperative outcomes given their propensity for low-energy falls, increased surgical risk, and poor bone quality. ${ }^{3,9,23,32}$

Management strategies for Type II odontoid fractures in the general and elderly populations have been extensively evaluated, yet the overwhelming majority of these studies have defined the elderly as patients older than 65 years. Due to their frequent medical comorbidities and increased susceptibility to operative complications, octogenarians constitute a medically distinct population; furthermore, geriatric patients constitute the fastest growing population segment in North America, collectively emphasizing the need for clarity in the management of Type II odontoid fractures in these patients. ${ }^{11,21,31,32}$

To our knowledge, 3 small prior studies have explicitly examined Type II odontoid fractures in octogenarians: one examined in-hospital complications only, another reviewed anterior screw fixation alone, and one compared posterior cervical fusion with $\mathrm{C} 1-2$ wire and autograft with collar immobilization in a 16-patient series. ${ }^{15,18,32}$ Correspondingly, ours is the first large-scale review of mortality after Type II odontoid fracture in octogenarian patients, with particular attention paid to the utility of baseline patient characteristics in predicting mortality after nonoperative or operative intervention.

\section{Methods \\ Patient Population}

A single-center prospectively maintained trauma database was reviewed using ICD-9 codes to identify all patients with C-2 fracture during the study period (19982014). Cervical CT images were independently reviewed by 2 resident neurosurgeons who were blinded to treatment modality and outcome. The presence of odontoid fracture was confirmed and classified according to the methodology described by Anderson and D'Alonzo. ${ }^{2}$ Instances of disagreement were resolved in a third review by an attending-level neurosurgeon.

\section{Data Acquisition}

Prospectively recorded data extracted from the trauma database included age, sex, date of injury, date of death, date of last follow-up, Glasgow Coma Scale (GCS) score, Abbreviated Injury Scale (AIS) score, Injury Severity Score (ISS), and ICD-9 codes, including procedure codes for all interventions, and diagnosis codes for cervical fractures and spinal cord injury (SCI) (2008 update to 2005 guidelines used for AIS score and ISS). ${ }^{5,12,13,22,33}$ No specific diagnosis codes for head injury were captured, and comorbid traumatic brain injury was evaluated via GCS score. Comorbidity indices were not included within the prospective database, and retrospective identification of comorbidity data immediately prior to presentation could not be captured with comparable reliability to prospective data, and were correspondingly excluded.

If neither mortality data nor 1 year of follow-up data were available, study staff attempted to contact the patient or next-of-kin by telephone to confirm vital status and date of death (where applicable). County death records were searched if attempted contact was unsuccessful. All communication employed telephone scripts, which were designed by supervising study staff to ensure HIPAA (Health Insurance Portability and Accountability Act) compliance, as well as collection of accurate, unbiased data. Appropriate training on patient informed consent and administration of the survey was provided prior to patient contact, and all study materials were reviewed and approved by our institutional review board.

\section{Statistical Analysis}

Primary end points were mortality at 30 days and 1 year, after either operative or nonoperative fracture management. Secondary end points were associations between mortality at 30 days and 1 year with SCI, presence of other cervical fracture, and GCS score, AIS score, and ISS at presentation. Statistical analysis included the Student ttest, chi-square test, Fisher's exact test, Kaplan-Meier univariate survival analysis, and Cox proportional hazards model. Analysis was completed using JMP (version 10.0.0, SAS Institute Inc.).

\section{Results}

One hundred thirteen octogenarian patients with Type II odontoid fractures were identified. Two patients who were managed with Halo rigid external fixation devices were excluded from this analysis. Information regarding mortality, 1-year follow-up, telephone contact with the patient or their consenting health care proxy, or county death record was available for $100 \%$ of the 111 study patients. Ninety-four patients were treated using nonoperative management strategies, including immobilization with a hard cervical collar $(85 \%)$. Seventeen patients underwent surgery $(15 \%)$. Of the 17 operations, there were 15 posterior and 2 anterior fusions, with the treatment approach decided on a case-by-case basis. All 15 posterior fusions were performed using a C1-2 segmental polyaxial screw and rod fixation technique, as described by Harms; anterior fusions employed a 1-screw technique. ${ }^{16,29}$ Both patients who underwent anterior surgery were noted to have radiographic C1-2 instability at follow-up, and subsequently underwent posterior surgery.

The mean age at injury was 87 years (range 80-104 years); there was a small but significant increase in age among patients who were managed nonoperatively (Table $1 ; 87$ vs 84 years, $p=0.0003$ ). Female patients represented a larger fraction of nonoperative patients, but this difference was not significant $(57 \%$ vs $35 \%, p=0.1)$. Mechanism of injury was comparable between the groups, with the overwhelming majority of patients presenting after a fall from standing height ( $86 \%$ vs $82 \%, \mathrm{p}=0.7)$, and smaller fractions attributable to motor vehicle accidents (7\% vs $6 \%, \mathrm{p}=0.8$ ) and other miscellaneous or unknown mechanisms (9\% vs $12 \%, \mathrm{p}=0.7)$.

Extent of injury and initial morbidity as assessed by AIS score and ISS on presentation was not significantly different between the groups (AIS score 3 vs $3, p=0.1$; ISS 12 vs $13, p=0.6$ [nonoperative vs surgery group]). GCS scores were equivalent, via analysis of the score as a continuous variable, and as a binary in which patients were classified relative to the threshold GCS score worse than 8 
TABLE 1. Baseline characteristics of nonoperative and surgery populations*

\begin{tabular}{lccc}
\hline \multicolumn{1}{c}{ Variable } & $\begin{array}{c}\text { Nonoperative } \\
(\mathrm{n}=94)\end{array}$ & $\begin{array}{c}\text { Surgery } \\
(\mathrm{n}=17)\end{array}$ & $\mathrm{p}$ Value \\
\hline Mean age, yrs & $87 \pm 5$ & $84 \pm 3$ & 0.0003 \\
\hline Female sex & $54(57)$ & $6(35)$ & 0.1 \\
\hline Mechanism & & & \\
\hline Fall & $81(86)$ & $14(82)$ & 0.7 \\
\hline MVA & $7(7)$ & $1(6)$ & 0.8 \\
\hline Other & $8(9)$ & $2(12)$ & 0.7 \\
\hline Additional cervical fracture & $37(39)$ & $6(35)$ & 0.8 \\
\hline SCI & $3(3)$ & $0(0)$ & 0.5 \\
\hline GCS score $\leq 8$ & $6(7)$ & $1(6)$ & 0.8 \\
\hline Mean GCS score (continu- & $14 \pm 3$ & $14 \pm 2$ & 0.5 \\
$\quad$ ous variable) & & & \\
\hline Mean AIS score & $3 \pm 0.5$ & $3 \pm 0.4$ & 0.1 \\
\hline Mean ISS & $12 \pm 6$ & $13 \pm 4$ & 0.6 \\
\hline
\end{tabular}

MVA = motor vehicle accident.

* Values are presented as the number of patients (\%) unless stated otherwise. Mean values are presented as the mean \pm SD. Boldface type indicates statistical significance.

(mean GCS score 14 vs 14, $\mathrm{p}=0.5$; percentage of patients $7 \%$ vs $6 \%, p=0.8$ [nonoperative vs surgery group]). The presence of additional cervical fracture or SCI was nonsignificant (additional fracture 39\% vs 35\%, $\mathrm{p}=0.8$; SCI $3 \%$ vs $0 \%, p=0.5$ [nonoperative vs surgery group]).

The overall mean time to death or last follow-up was 22 months (range 0-129 months); the mean follow-up duration was comparable ( 21 vs 28 months, $\mathrm{p}=0.3$ [nonoperative vs surgery group]; Table 2). A trend toward shorter median survival in the nonoperative population was observed, but this difference was not significant (40 vs 69 months, $\mathrm{p}=0.7)$. Differences in mortality were not significant in-hospital, at 30 days, or at 1 year $(12 \%$ vs $18 \%$, $\mathrm{p}=0.5 ; 27 \%$ vs $24 \%, \mathrm{p}=0.8 ; 41 \%$ vs $41 \%, \mathrm{p}=1.0$ [nonoperative vs surgery group]). Kaplan-Meier analysis did not show a significant survival advantage in either group (Fig. 1). Rate of hospital disposition to a nonhome facility was nonsignificant $(75 \%$ vs $92 \%, \mathrm{p}=0.2$ ).

Spinal cord injury was significantly associated with mortality, with a 30-day mortality OR of 8.3 (95\% CI 1.5$45.7, \mathrm{p}=0.005$; Table 3) and a 1-year mortality OR of 9.6 (95\% CI 1.1-82.7, $\mathrm{p}=0.01)$, as was GCS score worse than 8, with a 30-day mortality OR of 21.9 (95\% CI 2.5-192.6, $\mathrm{p}=0.005)$ and a 1-year mortality OR of 10.9 (95\% CI 1.394.5, $\mathrm{p}=0.01)$. When evaluated as continuous variables, GCS score, AIS score, and ISS were all significantly associated with 30-day and 1-year mortality; however, Cox modeling was not significant for any of these variables. The presence of additional cervical fracture was not associated with increased mortality at any time point.

\section{Discussion}

Type II odontoid fracture is associated with a high rate of morbidity among octogenarians, with 1-year mortality approaching 1-in-2 patients in the present series. This is
TABLE 2. Outcomes in nonoperative and surgery populations*

\begin{tabular}{llcc}
\hline \multicolumn{1}{c}{ Variable } & $\begin{array}{c}\text { Nonoperative } \\
(\mathrm{n}=94)\end{array}$ & $\begin{array}{c}\text { Surgery } \\
(\mathrm{n}=17)\end{array}$ & $\begin{array}{c}\mathrm{p} \\
\text { Value }\end{array}$ \\
\hline $\begin{array}{l}\text { Mean time to mortality/last } \\
\text { follow-up in mos }\end{array}$ & $21 \pm 24$ & $28 \pm 32$ & 0.3 \\
\hline Median survival in mos & 40 & 69 & 0.7 \\
\hline In-hospital mortality & $11(12)$ & $3(18)$ & 0.5 \\
\hline 30-day mortality & $25(27)$ & $4(24)$ & 0.8 \\
\hline 1-yr mortality & $39(41)$ & $7(41)$ & 1.0 \\
\hline Facility disposition & $57(75)$ & $12(92)$ & 0.2 \\
\hline * &
\end{tabular}

* Values are presented as the number of patients (\%) unless stated otherwise.

in stark contrast to actuarial data published by the Social Security Administration, which predicts median survival at 80,90 , and 100 years of age for men and women as 8.13 and 9.58 years, 4.00 and 4.75 years, and 2.09 and 2.41 years. ${ }^{35}$ Neither operative nor nonoperative management is associated with a survival benefit, and established predictors of poor prognosis-SCI, GCS score, AIS score, and ISS - are associated with significantly increased mortality, independent of management strategy.

The literature on Type II odontoid fractures in octogenarians is limited, but the conclusions of prior studies are broadly congruent with our own. In 1993, Hanigan et al. examined a retrospective series of 16 octogenarians with Type II odontoid fractures who were stratified into surgical and nonsurgical populations based on a fracture displacement threshold of $5 \mathrm{~mm}$, as well as their ability to tolerate surgery. ${ }^{15}$ Six patients were nonoperatively managed with rigid immobilization (1 Halo and 5 hard cervical collars), and 5 were treated via posterior fusion. Early mortality in their series was high with 5 in-hospital deaths, and at 1 year, 9 patients had died, for an all-cause mortality of 56\%; there was no significant difference between the groups. The authors concluded that fibrous fusion

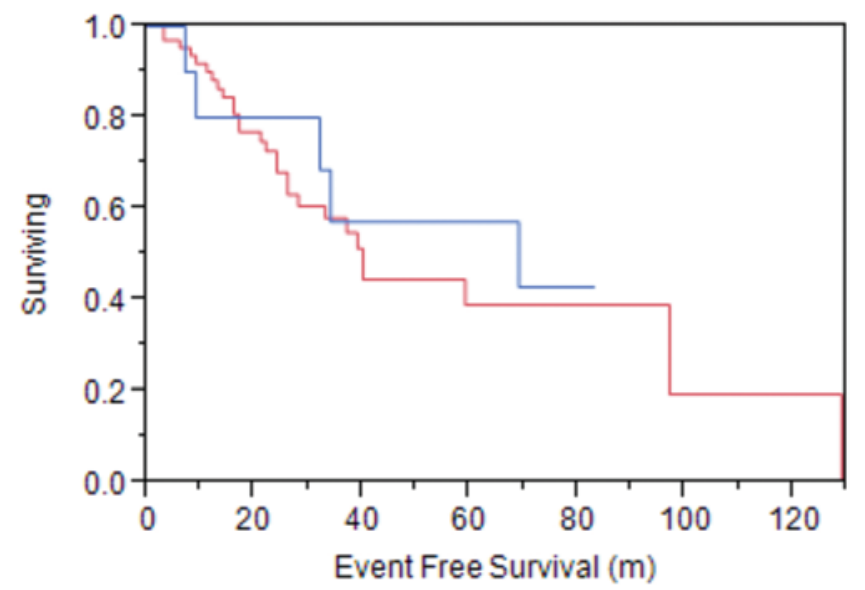

Nonoperative cohort

Operative cohort $\mathrm{p}=0.7$

FIG. 1. Kaplan-Meier survival analysis comparing nonoperative and operative populations. Figure is available in color online only. 
TABLE 3. Associations between patient characteristics and outcomes (all patients)*

\begin{tabular}{|c|c|c|c|c|c|}
\hline \multirow[b]{2}{*}{ Variable } & \multicolumn{2}{|c|}{ 30-Day Mortality } & \multicolumn{2}{|c|}{ 1-Yr Mortality } & \multirow{2}{*}{$\begin{array}{c}\text { Cox Proportiona } \\
\text { Hazards }\end{array}$} \\
\hline & OR $(95 \% \mathrm{Cl})$ & $p$ Value & OR $(95 \% \mathrm{Cl})$ & $p$ Value & \\
\hline $\mathrm{SCl}$ & $8.3(1.5-45.7)$ & 0.005 & $9.6(1.1-82.7)$ & 0.01 & 0.2 \\
\hline Additional cervical fracture & $1.2(0.5-2.8)$ & 0.7 & $1.0(0.5-2.2)$ & 0.9 & 0.9 \\
\hline GCS score $\leq 8$ & $21.9(2.5-192.6)$ & 0.005 & $10.9(1.3-94.5)$ & 0.01 & 0.31 \\
\hline GCS score (continuous variable) & & 0.004 & & 0.01 & 0.2 \\
\hline AIS score & & 0.02 & & 0.2 & 0.07 \\
\hline ISS & & 0.04 & & 0.07 & 0.7 \\
\hline
\end{tabular}

* Boldface type indicates statistical significance.

rates were comparable and adequate under either strategy, and recommended the 5-mm threshold as a preliminary guideline for indicating surgery in appropriate candidates.

Smith et al. published a longer retrospective series of 80 patients, yet the authors only evaluated in-hospital complications and mortalities. ${ }^{32}$ Findings included comparable mortality in the nonoperative and operative groups at $15 \%$ and $12 \%$, a difference that was nonsignificant. Overall complication rates were comparable, although surgical patients were significantly more likely to have a prolonged hospital stay and to require tracheostomy.

More recently, Hénaux et al. reviewed a retrospective series of 11 Type II odontoid fractures in octogenarians; however, this analysis focused on anterior screw fixation, and selected fusion rate and quality of life as primary end points..$^{18}$ No perioperative mortalities were reported, and all-cause 1 -year mortality was $18 \%$. Stable bony or fibrous union was observed in the remaining 9 patients by 3 months. Although these results are promising and reflect a possible improvement from comparable series describing posterior fusion or nonoperative strategies, the small study size and lack of comparison groups substantially limits interpretation and generalization of the findings.

The review by Hénaux et al. prompts essential reflection on the choice of approach to C-2 fractures, particularly within the octogenarian population. Our institutional practice reflects national trends in that no specific algorithm has been developed and tested-rather, general overarching guidelines shape individualized clinical decisions. In younger patients with appropriate fracture geometry, anterior approaches may be selected to preserve motion; however, in elderly patients who are considered surgical candidates, posterior approaches are preferred due to the lower incidence of dysphagia and pulmonary complications, as well as higher fusion rates. ${ }^{7,34}$ As our results demonstrate, these are by no means fixed guidelines, and an anterior approach is considered in select patients, with the goal of optimizing and personalizing all surgical care; to this same end, a trial is ongoing at our institution to objectively and prospectively evaluate dysphagia and airway outcomes after anterior cervical spine surgery.

Two additional studies conducted on larger cohorts substratified their analyses such that certain outcomes could be evaluated discretely with respect to octogenarian patients. Boakye et al. performed a retrospective propensity score-matched cohort analysis using the Nationwide Inpatient Sample Database, comparing Halo immobiliza- tion with surgical intervention in 3758 patients of all ages. ${ }^{4}$ Overall results showed no in-hospital mortality difference between the groups, with significant associations between surgical management and increased complication rates, lengths-of-stay, hospital charges, and discharges to nonhome facilities. Perhaps more importantly, among octogenarians, complications were noted to occur at a 3.5-fold incidence compared with patients younger than 60 years across all groups, supporting the conclusion that odontoid fracture is an extraordinarily morbid injury among octogenarians.

Similarly, Schoenfeld et al. published a retrospective cohort study of 156 patients older than 65 years in which they examined the effect of treatment strategy and medical comorbidities on mortality substratified by age groups $65-74,75-84$, and older than 85 years. ${ }^{30}$ Although overall results showed decreased mortality in the surgery cohort at 3 months (11\% vs $21 \%)$ and at 1 year (25\% vs $36 \%)$, overall mortality was still quite high, reaching $39 \%$ at 3 years. Additionally, a nonsignificant trend was observed between increasing age and the hazard ratio associated with surgery, which was observed to be $0.4,0.8$, and 1.9 in the 65- to 74-year, 75- to 84-year, and older than 85-yearold cohorts, respectively. However, given that these findings were not significant in any subgroup, the definitive conclusion remains congruent with our own-that Type II odontoid fractures are highly morbid in elderly patients, independent of management strategy.

The results of the present study should also be considered with respect to the literature on Type II odontoid fractures in all patients older than 65 years, which is at once more robust and more confounding. Of particular interest is Fehlings and colleagues' multicenter prospective cohort study of 159 patients, which focused on predictors of treatment outcomes. This analysis concluded that the OR for treatment failure was 1.08 for each year of age, with an overall treatment failure odds of 3.09 for nonsurgical management. ${ }^{10}$ Although these findings support early operative intervention for Type II odontoid fractures, they also suggest that an age threshold exists, beyond which the advantage may reverse in favor of nonsurgical management.

In an extensive and detailed review of the literature on odontoid fractures in patients older than 65 , Pal et al. ${ }^{24}$ highlighted the lack of Class I evidence or randomized trials underlying the lack of clarity regarding optimal treatment. A key issue the authors identified is the adequacy 
of fibrous in lieu of bony union: although several recent studies have suggested this as an appropriate therapeutic target, other authors argue that the risk of delayed myelopathy outweighs the risks of surgery and correspondingly advocate strongly in favor of surgical intervention. ${ }^{1,15,20,24,28}$

Surveying the literature at large, delayed myelopathy is an exceedingly rare outcome, and progression to myelopathy from either fibrous union or frank nonunion may take many years, as demonstrated by the series by Hart et al., in which no cases of delayed myelopathy or worsening spinal instability were seen in a series of 5 patients all aged 7785 years who were followed for an average of 55 months. ${ }^{17}$ Other reports have only observed this rare complication at a significant delay, often more than a decade after surgery, even in younger, more active patients. ${ }^{24,25}$ Taking Fehlings and colleagues' findings together with those of our own study, ${ }^{10}$ we again conclude that octogenarians with Type II odontoid fractures are subject to high mortality-regardless of treatment modality-and that the profound impact of the primary injury dramatically overshadows the theoretical risk of delayed myelopathy.

The ultimate implications of our study remain unclear, particularly given its limitations. Although patients were enrolled and tracked prospectively, there was no randomization, the surgical group was small, and follow-up was limited to 1 year. Within the scope of our statistical analysis, the disproportionate sample sizes do not jeopardize the accuracy of our results; however, given that there were only 17 patients in the operative group, the power of the study is limited, increasing the probability of a Type II error-that is to say, a false negative, or failure to detect a significant association between mortality and intervention. Quality-of-life metrics such as the Neck Disability Index were not assessed; however, given that these data were not collected prospectively and that 1 -year mortality was over $40 \%$, a retrospective survey would have been hindered by significant selection and recall biases. In spite of extensive chart review, study staff could not definitively establish which patients were offered surgery, as well as the influence of related discussions with patients' families. Correspondingly, it is impossible to definitively establish the prevalence of surgical candidacy among this population, only the actual rate at which surgery was actually performed.

Comorbidity analysis using the Charlson Comorbidity Index or a comparable metric could not be performed using the available data, potentially providing a source of confounding. Under such circumstances, one would anticipate that any significant difference in performance status would confer a survival advantage on the surgical cohort; that this was not observed is reassuring in terms of potential bias, and underscores our conclusion that operative intervention in the octogenarian population should be approached with caution. Such speculation also invites the question, "Did surgery confer increased mortality in patients who were healthier at baseline, falsely equivocating outcomes in two fundamentally non-equivalent populations?" Indeed, such a confounded reality may underlie our findings; however, that possibility does not alter our general conclusions that among octogenarians, surgery may not confer the same benefit it does among younger patients, and that further study is mandated to better characterize the role for operative intervention in this population.

Finally, bony and fibrous fusion rates were not evaluated in the present study, in part due to the preceding findings described above, regarding the overstated risk of delayed myelopathy and the corresponding implication that nonunion may be less relevant to a patient population with a poor prognosis, a limited lifespan, or both. Notwithstanding, it is our belief that a focused radiographic review of Type II odontoid fractures-both at the time of injury and in follow-up after each management strategymay provide additional insight into the natural history of the disease and its ideal treatment in this population. This is an area of active investigation by our group and constitutes one of the crucial directions for future study following from our present work, alongside a prospective trial focused specifically on outcomes after operative or nonoperative management in octogenarians.

\section{Conclusions}

As compared with prior analyses on all patients older than 65 years, which have generally-but not universally-supported early operative intervention, our data do not demonstrate a survival advantage associated with either operative or nonoperative management in octogenarians with Type II odontoid fractures. Although some appropriately selected patients may benefit from operative intervention, surgery should be approached with pronounced trepidation in this population, given the lack of a clear and significant survival advantage in the face of increased surgical risk.

Interpretation of our own data in concert with previous findings is challenging, given the study heterogeneity, dominance of Class III evidence, and inherent publication bias favoring the report of positive studies and idealized data. Nevertheless, we anticipate that our findings will provide new and data-driven insight into the significant mortality associated with odontoid fractures in this population, and helpfully inform conversations with patients and families regarding expectations and prognosis after the recommended treatment, with the ultimate goal of providing individualized neurosurgical care.

\section{References}

1. Anderson LD, D'Alonzo RT: Fractures of the odontoid process of the axis. J Bone Joint Surg Am 56:1663-1674, 1974

2. Anderson LD, D'Alonzo RT: Fractures of the odontoid process of the axis. 1974. J Bone Joint Surg Am 86-A:2081, 2004

3. Apuzzo ML, Heiden JS, Weiss MH, Ackerson TT, Harvey JP, Kurze T: Acute fractures of the odontoid process. An analysis of 45 cases. J Neurosurg 48:85-91, 1978

4. Boakye M, Arrigo RT, Kalanithi PS, Chen YR: Impact of age, injury severity score, and medical comorbidities on early complications after fusion and halo-vest immobilization for C2 fractures in older adults: a propensity score matched retrospective cohort study. Spine (Phila Pa 1976) 37:854-859, 2012

5. Civil ID, Schwab CW: The Abbreviated Injury Scale, 1985 revision: a condensed chart for clinical use. J Trauma 28:87-90, 1988 
6. Clark CR, White AA III: Fractures of the dens. A multicenter study. J Bone Joint Surg Am 67:1340-1348, 1985

7. Dailey AT, Hart D, Finn MA, Schmidt MH, Apfelbaum RI: Anterior fixation of odontoid fractures in an elderly population. J Neurosurg Spine 12:1-8, 2010

8. Dunn ME, Seljeskog EL: Experience in the management of odontoid process injuries: an analysis of 128 cases. Neurosurgery 18:306-310, 1986

9. Fassett DR, Harrop JS, Maltenfort M, Jeyamohan SB, Ratliff JD, Anderson DG, et al: Mortality rates in geriatric patients with spinal cord injuries. J Neurosurg Spine 7:277-281, 2007

10. Fehlings MG, Arun R, Vaccaro AR, Arnold PM, Chapman JR, Kopjar B: Predictors of treatment outcomes in geriatric patients with odontoid fractures: AOSpine North America multi-centre prospective GOF study. Spine (Phila Pa 1976) 38:881-886, 2013

11. Frangen TM, Zilkens C, Muhr G, Schinkel C: Odontoid fractures in the elderly: dorsal $\mathrm{C} 1 / \mathrm{C} 2$ fusion is superior to halovest immobilization. J Trauma 63:83-89, 2007

12. Gennarelli TA, Wodzin E (eds): The Abbreviated Injury Scale 2005 - Update 2008. Chicago, IL: Association for the Advancement of Automotive Medicine, 2008

13. Gennarelli TA, Wodzin E: AIS 2005: a contemporary injury scale. Injury 37:1083-1091, 2006

14. Hadley MN, Browner C, Sonntag VK: Axis fractures: a comprehensive review of management and treatment in 107 cases. Neurosurgery 17:281-290, 1985

15. Hanigan WC, Powell FC, Elwood PW, Henderson JP: Odontoid fractures in elderly patients. J Neurosurg 78:32-35, 1993

16. Harms J, Melcher RP: Posterior C1-C2 fusion with polyaxial screw and rod fixation. Spine (Phila Pa 1976) 26:2467-2471, 2001

17. Hart R, Saterbak A, Rapp T, Clark C: Nonoperative management of dens fracture nonunion in elderly patients without myelopathy. Spine (Phila Pa 1976) 25:1339-1343, 2000

18. Hénaux PL, Cueff F, Diabira S, Riffaud L, Hamlat A, Brassier $\mathrm{G}$, et al: Anterior screw fixation of type IIB odontoid fractures in octogenarians. Eur Spine J 21:335-339, 2012

19. Kirankumar MV, Behari S, Salunke P, Banerji D, Chhabra DK, Jain VK: Surgical management of remote, isolated type II odontoid fractures with atlantoaxial dislocation causing cervical compressive myelopathy. Neurosurgery 56:10041012,2005

20. Lieberman IH, Webb JK: Cervical spine injuries in the elderly. J Bone Joint Surg Br 76:877-881, 1994

21. Lind B, Nordwall A, Sihlbom H: Odontoid fractures treated with halo-vest. Spine (Phila Pa 1976) 12:173-177, 1987

22. MacKenzie EJ, Shapiro S, Eastham JN: The Abbreviated Injury Scale and Injury Severity Score. Levels of inter- and intrarater reliability. Med Care 23:823-835, 1985

23. Malik SA, Murphy M, Connolly P, O’Byrne J: Evaluation of morbidity, mortality and outcome following cervical spine injuries in elderly patients. Eur Spine J 17:585-591, 2008

24. Pal D, Sell P, Grevitt M: Type II odontoid fractures in the elderly: an evidence-based narrative review of management. Eur Spine J 20:195-204, 2011

25. Paradis GR, Janes JM: Posttraumatic atlantoaxial instability: the fate of the odontoid process fracture in 46 cases. $\mathbf{J}$ Trauma 13:359-367, 1973

26. Pepin JW, Bourne RB, Hawkins RJ: Odontoid fractures, with special reference to the elderly patient. Clin Orthop Relat Res (193):178-183, 1985
27. Ryan MD, Henderson JJ: The epidemiology of fractures and fracture-dislocations of the cervical spine. Injury 23:38-40, 1992

28. Ryan MD, Taylor TK: Odontoid fractures in the elderly. J Spinal Disord 6:397-401, 1993

29. Sasso R, Doherty BJ, Crawford MJ, Heggeness MH: Biomechanics of odontoid fracture fixation. Comparison of the one- and two-screw technique. Spine (Phila Pa 1976) 18:1950-1953, 1993

30. Schoenfeld AJ, Bono CM, Reichmann WM, Warholic N, Wood KB, Losina E, et al: Type II odontoid fractures of the cervical spine: do treatment type and medical comorbidities affect mortality in elderly patients? Spine (Phila Pa 1976) 36:879-885, 2011

31. Smith HE, Kerr SM, Fehlings MG, Chapman J, Maltenfort M, Zavlasky J, et al: Trends in epidemiology and management of type II odontoid fractures: 20 -year experience at a model system spine injury tertiary referral center. J Spinal Disord Tech 23:501-505, 2010

32. Smith HE, Kerr SM, Maltenfort M, Chaudhry S, Norton R, Albert TJ, et al: Early complications of surgical versus conservative treatment of isolated type II odontoid fractures in octogenarians: a retrospective cohort study. J Spinal Disord Tech 21:535-539, 2008

33. Teasdale G, Jennett B: Assessment of coma and impaired consciousness. A practical scale. Lancet 2:81-84, 1974

34. Tian NF, Hu XQ, Wu LJ, Wu XL, Wu YS, Zhang XL, et al: Pooled analysis of non-union, re-operation, infection, and approach related complications after anterior odontoid screw fixation. PLoS One 9:e103065, 2014

35. United States Census Bureau: 2010 census shows 65 and older population growing faster than total U.S. population. US Census Bureau Newsroom. November 30, 2011. (https:// www.census.gov/newsroom/releases/archives/2010_census/ cb11-cn192.html) [Accessed June 29, 2016]

\section{Disclosures}

The authors report no conflict of interest concerning the materials or methods used in this study or the findings specified in this paper.

\section{Author Contributions}

Conception and design: Clarke, Graffeo, Perry, Mallory. Acquisition of data: Graffeo, Perry, Puffer, Carlstrom, Chang, Mallory. Analysis and interpretation of data: Graffeo, Perry. Drafting the article: Graffeo. Critically revising the article: Graffeo, Perry. Reviewed submitted version of manuscript: Clarke, Graffeo. Approved the final version of the manuscript on behalf of all authors: Clarke. Statistical analysis: Graffeo. Administrative/technical/material support: Graffeo. Study supervision: Clarke.

\section{Supplemental Information}

\section{Previous Presentations}

This paper was presented at the Congress of Neurological Surgeons Annual Meeting in New Orleans, Lousiana, September 26-30, 2015.

\section{Correspondence}

Michelle J. Clarke, Department of Neurologic Surgery, Mayo Clinic, 200 First St. SW, Rochester, MN 55905. email: clarke. michelle@mayo.edu. 